\title{
QUALITY COMPARISON OF DUPLEX CARTON 350 GR/M2 BASED ON SNI-0123: 2008
}

\section{PERBANDINGAN MUTU KARTON DUPLEX 350 GR/M2 BERDASARKAN SNI-0123:2008}

\author{
Lala Hucadinota Ainul Amri ${ }^{a^{*}}$, Mawan Nugraha ${ }^{a}$, Nazula Nurul Zahra ${ }^{a}$ \\ a Teknik Grafika, Politeknik Negeri Media Kreatif, Indonesia \\ *Email: lalahuca@polimedia.ac.id
}

\begin{abstract}
Duplex cartons will be one type of carton that is widely used as a primary or second packaging. Duplex cartons have hygroscopic properties that can be salted on the physical and quality of the carton duplex. The value of this Final Task paper is the way of quality of cardboard in the field and the efforts of the process and who is in the field champion of The Indonesian National Standard (SNI 0123:2008). While the purpose of this writing is For those who know the process of creation of duplex carton quality $350 \mathrm{gr} / \mathrm{m} 2$, To understand the results of the creation of the quality of both duplex cartons from different companies, and For to dye the quality of cartons $350 \mathrm{gr} / \mathrm{m} 2$ in the market of different companies. Which method in writing this Final Task paper is the Task Related to Indonesian National Standards (SNI 0123:2008). Located from the creation and duparan quality of its own results, the two duplex cartons there are different qualities, for the production of PT X. Cobb value which is passionate and quality questions according to SNI 0123:2008 while for the production of PT $Y$. brightness value who can not be questioned sni 0123:2008. SNI 0123:2008 was prepared with the purpose of standardization, but the standard provisions were not met and not supervised in companies that do not apply sni standard 0123:2008, but in companies that apply sni standard 0123:2008 found also incompatible, therefore it is recommended to be carried out monitoring periodically.
\end{abstract}

Keywords-Quality duplex carton, Duplex Carton, SNI 0123:2008

Abstrak-Karton duplex merupakan salah satu jenis karton yang banyak digunakan sebagai kemasan primer maupun sekunder. Karton duplex memliki sifat higroskopis yang dapat menyebabkan perubahan pada fisik dan mutu dari karton duplex. Rumusan masalah pada karya tulis Tugas Akhir ini meliputi bagaimana kualitas mutu karton yang ada di lapangan berikut 
proses pengujiannya serta menentukan apakah produk yang ada di lapangan tersebut memenuhi Standar Nasional Indonesia (SNI 0123:2008). Sedangkan tujuan penulisan ini adalah Untuk mengetahui proses pengujian mutu karton duplex $350 \mathrm{gr} / \mathrm{m} 2$, Untuk memahami hasil dari pengujian mutu kedua karton duplex dari perusahaan yang berbeda, dan Untuk membandingkan mutu karton duplex $350 \mathrm{gr} / \mathrm{m} 2$ yang beredar dipasaran dari perusahaan yang berbeda. Metode yang digunakan dalam penulisan karya tulis Tugas Akhir ini adalah Pengujian berdasarkan Standar Nasional Indonesia (SNI 0123:2008). Berdasarkan dari hasil pengujian serta perbandingan mutu didapatkan hasil, bahwa kedua karton duplex memiliki mutu yang berbeda, untuk produksi PT X. nilai Cobb yang didapat tidak memenuhi persyaratan mutu menurut SNI 0123:2008 sedangkan untuk produksi PT Y. nilai brightness yang didapat tidak memenuhi persyaratan mutu menurut SNI 0123:2008. SNI 0123:2008 disusun dengan tujuan standarisasi, namun ketentuan standar tidak terpenuhi dan tidak terawasi pada perusahaan yang tidak menerapkan standar SNI 0123:2008, namun di perusahaan yang menerapkan standar SNI 0123:2008 ditemukan juga ketidak sesuaian, untuk itu disarankan dilaksanakan pemantauan secara berkala.

\section{Kata Kunci-Mutu karton duplex, Karton duplex, SNI 0123:2008}

\section{PENDAHULUAN}

aat ini kemasan berbahan kertas dan karton banyak dijumpai dibanyak tempat seperti, supermarket, pasar tradisional, toko kelontong, restaurant, apotek, rumah sakit, dan lain-lain. Hal ini disebabkan karena kemasan berbahan kertas dan karton memiliki biaya produksi yang relatif murah serta kegunaannya yang luas dan sebagai alternatif pengganti plastik. Namun, kemasan kertas dan karton juga memiliki kelemahan, yaitu tidak tahan terhadap air, mudah sobek, mudah terbakar, dan memiliki sifat hygroskopis, yaitu dapat dipengaruhi oleh kelembaban udara, sifat hygroskopisinilah yang dapat merubah sifat fisik dari suatu kertas. Sifat fisik dari

kertas sendiri terdiri dari berat dasar, ketebalan, kekuatan permukaan, daya serap air dan minyak, kekuatan lipat, kekuatan sobek, kekakuan, kekuatan retak dan kekuatan tarik.

Kualitas pada kemasan kertas dan karton sangat tergantung dari bahan dan pada proses pembuatannya, karena pada masingmasing jenis kertas dan karton mempunyai ciri khas tersendiri yang mampu mempengaruhi mutu dari kertas dan karton.

Terdapat beberapa persyaratan untuk mengetahui mutu dari kertas dan 
kartonberdasarkan Standar Nasional menggunakan alat objektif dan baku.

Indonesia, yaitu berat dasar, ketebalan, rapat massa, daya serap air, daya serap minyak, komposisi lembaran, ketahanan cabut lapisan atas, sifat pelipatan, brightness, dan kadar air. Saat ini banyak kita jumpai kemasan berbahan kertas dan karton, khususnya karton duplex, tetapi kita tidak mengatahui mutu dari kemasan tersebut, maka dari itu diperlukan pengujian perbandingan mutu dari karton duplex yang beredar di pasaran untuk mengetahui mutunya.

Berdasarkan Uraian diatas, maka peneliti tertarik untuk mengambil peneltian Mutu Karton Duplex 350350 gr/m2 Produksi PT. X. dan PT. Y.Berdasarkan SNI 0123:2008. Agar dapat bermanfaat menambah keilmuan serta menjadi acuan industri.

\section{METODE}

Metode yang digunakan dalam penelitian ini adalah metode eksperimen dan campuran, dijelaskan secara rinci sebagai berikut :

\section{A. Metode Penelitian}

Metode penelitian yang digunakan pada penelitian ini adalah dengan menggunakan metode pendekatan kuantitatif, karena dalam metode kuantitatif melibatkan perhitungan angka atau kuantifikasi data yang diperoleh melalui pengukuran dengan
B. Metode Pengujian

Metode ini digunakan untuk mendapatkan data-data yang akurat terkait dengan penelitian ini. Pengujian dilakukan di Laboratorium bahan grafika Politeknik Negeri Media Kreatif Jakarta.

\section{Metode Observasi}

Metode observasi ialah pengamatan langsung menggunakan alat indera atau instrument sebagai alat bantu untuk penginderaan suatu subjek atau objek yang juga merupakan basis sains. (Kurniawan, 2011:10).

\section{Metode Kepustakaan}

Metode ini digunakan untuk melengkapi data dan informasi yang bersifat teori, peneliti menggunakan data dari berbagai sumber referensi seperti SNI/ISO, jurnal, dan internet dengan tema yang sesuai dengan pembahasan dalam penelitian ini.

\section{HASIL DAN PEMBAHASAN}

Pengujian telah dilaksanakan dengan baik. Dari pengujian mutu karton duplex yang telah peneliti lakukan di Laboratorium Pengujian Bahan Politeknik Negeri Media Kreatif Jakarta, mendapatkan hasil data perbandingan mutu dari hasil uji kedua karton duplex $350 \mathrm{~g} / \mathrm{m} 2$ produksi PT X. dan PT Y.

berdasarkan Standar Nasional Indonesia terkait persyaratan mutu karton duplex (SNI 
0123:2008).

Terdapat 9 parameter pengujian yang diuji, diantaranya komposisi lembaran, gramatur kertas, rapat massa, derajat putih, ketahanan cabut kertas lapisan atas, penetrasi minyak lapisan atas, daya serap air lapisan atas, sifat pelipatan, dan kadar air. Berikut hasil dan perbandingan dari pengujian yang telah dilakukan peneliti :

Tabel 1. Data Pengujian Karton Duplex 350 g/m2 Produksi PT X. dan PT Y.

\begin{tabular}{|c|c|c|c|c|c|c|c|c|c|c|}
\hline \multirow{2}{*}{\multicolumn{2}{|c|}{$\begin{array}{l}\text { No Jenis } \\
\text { Pengujian }\end{array}$}} & \multirow[t]{2}{*}{$\begin{array}{l}\text { SNI 0123- } \\
2008\end{array}$} & \multicolumn{3}{|c|}{$\begin{array}{c}\text { Hasil pengujian karton } \\
\text { duplex350 g/m } m^{2} \\
\text { produksi PT X. }\end{array}$} & \multirow[t]{2}{*}{ Ket. } & \multicolumn{3}{|c|}{$\begin{array}{c}\text { Hasil pengujian karton } \\
\text { duplex 350g/m2 Produksi } \\
\text { PT Y. }\end{array}$} & \multirow[t]{2}{*}{ Ket. } \\
\hline & & & Nilai & \pm SD & $\% \mathrm{~V}$ & & Nilai & $\pm \mathrm{SD}$ & $\% \mathrm{~V}$ & \\
\hline 1 & $\begin{array}{l}\text { Komposisi } \\
\text { lembaran }\end{array}$ & $\begin{array}{l}\text { Lapisan atas } \\
\text { dari pulp } \\
\text { kimia putih }\end{array}$ & $\begin{array}{l}\text { Pulp } \\
\text { kimia }\end{array}$ & - & - & Sesuai & $\begin{array}{l}\text { Pulp } \\
\text { kimia }\end{array}$ & - & - & Sesuai \\
\hline 2 & $\begin{array}{l}\text { Gramatur } \\
\text { kertas }\end{array}$ & $\begin{array}{c}350 \\
\mathrm{~g} / \mathrm{m} 2 \mathrm{dengan} \\
\text { variasi maks } \\
4 \% \\
\end{array}$ & $\begin{array}{l}352,96 \\
9 \mathrm{~g} / \mathrm{m}^{2}\end{array}$ & $\begin{array}{l}5,08 \\
\mathrm{~g} / \mathrm{m}^{2}\end{array}$ & $\begin{array}{r}1,4 \\
\%\end{array}$ & Sesuai & $\begin{array}{c}347,483 \\
\mathrm{~g} / \mathrm{m}^{2}\end{array}$ & $\begin{array}{l}2,24 \\
\mathrm{~g} / \mathrm{m}^{2}\end{array}$ & $0,6 \%$ & Sesuai \\
\hline 3 & $\begin{array}{l}\text { Rapat } \\
\text { Massa }\end{array}$ & $\begin{array}{c}\text { Min.700 } \\
\mathrm{kg} / \mathrm{m} 3\end{array}$ & $\begin{array}{c}802,74 \\
9 \\
\mathrm{~kg} / \mathrm{m}^{3} \\
\end{array}$ & - & - & Sesuai & $\begin{array}{c}842,642 \\
\mathrm{~kg} / \mathrm{m}^{3}\end{array}$ & - & - & Sesuai \\
\hline 4 & $\begin{array}{l}\text { Derajat } \\
\text { putih } \\
\text { lapisan } \\
\text { atas }\end{array}$ & Min.76\% & $\begin{array}{c}80,24 \\
\%\end{array}$ & $\begin{array}{l}0,31 \\
6 \%\end{array}$ & $\begin{array}{r}0,3 \\
\%\end{array}$ & Sesuai & $60,54 \%$ & $\begin{array}{c}15,95 \\
\%\end{array}$ & $26 \%$ & $\begin{array}{l}\text { Tidak } \\
\text { sesuai }\end{array}$ \\
\hline & $\begin{array}{l}\text { Ketahanan } \\
\text { cabut } \\
\text { lapisan } \\
\text { atas }\end{array}$ & $\begin{array}{l}\text { Min. } 300 \\
\text { Poise } \mathrm{m} / \mathrm{s}\end{array}$ & & & & & & & & \\
\hline & $\begin{array}{l}\text { MD } \\
\text { Pendulum }\end{array}$ & & Baik & - & - & Sesuai & Baik & - & - & Sesuai \\
\hline & $\begin{array}{l}\mathrm{CD} \\
\text { Pendulum }\end{array}$ & & Baik & - & - & Sesuai & Baik & - & - & Sesuai \\
\hline & $\begin{array}{l}\text { Penetrasi } \\
\text { Minyak } \\
\text { lapisan } \\
\text { atas }\end{array}$ & $7-15 \mathrm{~mm}$ & $\begin{array}{l}7,866 \\
\mathrm{~mm}\end{array}$ & $\begin{array}{l}0,55 \\
\mathrm{~mm}\end{array}$ & $7 \%$ & Sesuai & $\begin{array}{c}8,311 \\
\mathrm{~mm}\end{array}$ & $\begin{array}{c}0,350 \\
\mathrm{~mm}\end{array}$ & $4,2 \%$ & Sesuai \\
\hline 7 & $\begin{array}{l}\text { Daya } \\
\text { Serap Air } \\
\text { (Cobb) } \\
\text { lapisan } \\
\text { atas } \\
\end{array}$ & $\begin{array}{l}20-40 \\
\mathrm{~g} / m 2\end{array}$ & $\begin{array}{l}46,2 \\
\mathrm{~g} / \mathrm{m}^{2}\end{array}$ & $\begin{array}{l}2,57 \\
5 \\
\mathrm{~g} / \mathrm{m}^{2}\end{array}$ & $5 \%$ & $\begin{array}{l}\text { Tidak } \\
\text { sesuai }\end{array}$ & $\begin{array}{c}22,702 \\
\mathrm{~g} / \mathrm{m}^{2}\end{array}$ & $\begin{array}{l}3,56 \\
4 \\
g / m^{2}\end{array}$ & $15 \%$ & Sesuai \\
\hline & $\begin{array}{l}\text { Sifat } \\
\text { Lipatan }\end{array}$ & & & & & & & & & \\
\hline 8 & MD & Tidak patah & Baik & - & - & Sesuai & Baik & - & - & Sesuai \\
\hline & $\mathrm{CD}$ & & Retak & - & - & $\begin{array}{l}\text { Tidak } \\
\text { Sesuai }\end{array}$ & Retak & - & - & $\begin{array}{l}\text { Tidak } \\
\text { Sesuai }\end{array}$ \\
\hline 9 & Kadar air & Maks.10\% & $5,15 \%$ & - & - & Sesuai & $4 \%$ & - & - & Sesuai \\
\hline
\end{tabular}


Dari Tabel. 1 yang merupakan hasil dan produksi dua perusahaan yang berbeda perbandingan dari pengujian mutu karton terhadap Standar Nasional Indonesia duplex $350 \mathrm{~g} / \mathrm{m} 2$ produksi PT X. dan PT Y. persyaratan mutu karton duplex.

berdasarkan Standar Nasional Indonesia karton duplex (SNI 0123:2008) terdapat beberapa hasil pengujian yang sesuai dan juga tidak sesuai dengan SNI karton duplex yang disebabkan oleh faktor-faktor tertentu. Pengujian ini bertujuan untuk mengetahui serta membandingkan mutu karton duplex

Setelah melakukan pengujian dan perbandingan mutu karton duplex $350 \mathrm{~g} / \mathrm{m} 2$ produksi PT X. dan PT Y. berdasarkan Standar Nasional Indonesia terkait persyaratan mutu karton duplex (SNI 0123:2008), Mendapatkan perbandingan utama data hasil sebagai berikut:

Tabel 2. Data Perbandingan Utama Karton Duplex 350 g/m2 Produksi PT X. dan PT Y.

\begin{tabular}{|c|c|c|c|c|c|c|}
\hline No & $\begin{array}{c}\text { Jenis } \\
\text { pengujian }\end{array}$ & SNI 0123 :2008 & $\begin{array}{c}\text { Hasil uji karton } \\
\text { duplex Poduksi } \\
\text { PT X. }\end{array}$ & $\begin{array}{c}\text { Ketera } \\
\text { ngan }\end{array}$ & $\begin{array}{c}\text { Hasil uji karton } \\
\text { duplex Poduksi } \\
\text { PT Y. }\end{array}$ & $\begin{array}{c}\text { Ketera } \\
\text { ngan }\end{array}$ \\
\hline 1. & $\begin{array}{l}\text { Komposisi } \\
\text { lembaran }\end{array}$ & $\begin{array}{l}\text { lapisan atas dari } \\
\text { pulp kimia putih }\end{array}$ & Pulp kimia & Sesuai & Pulp kimia & Sesuai \\
\hline 2. & $\begin{array}{c}\text { Gramatur } \\
\text { kertas }\end{array}$ & $\begin{array}{l}350 \mathrm{~g} / \mathrm{m}^{2} \text { dengan } \\
\text { variasi maks } 4 \%\end{array}$ & $352,969 \mathrm{~g} / \mathrm{m}^{2}$ & Sesuai & $347,483 \mathrm{~g} / \mathrm{m}^{2}$ & Sesuai \\
\hline 3. & $\begin{array}{l}\text { Rapat } \\
\text { Massa }\end{array}$ & Min. $700 \mathrm{~kg} / \mathrm{m}^{3}$ & $802,74 \mathrm{~kg} / \mathrm{m}^{3}$ & Sesuai & $842,642 \mathrm{~kg} / \mathrm{m}^{3}$ & Sesuai \\
\hline 4. & $\begin{array}{l}\text { Derajat } \\
\text { putih }\end{array}$ & Min.76\% & $80,24 \%$ & Sesuai & $60,54 \%$ & $\begin{array}{l}\text { Tidak } \\
\text { Sesuai }\end{array}$ \\
\hline \multirow{2}{*}{5.} & $\begin{array}{c}\text { Ketahanan } \\
\text { cabut kertas }\end{array}$ & Min. 300 Poise $\mathrm{m} / \mathrm{s}$ & & & & \\
\hline & $\begin{array}{c}\mathrm{MD} \\
\mathrm{CD}\end{array}$ & 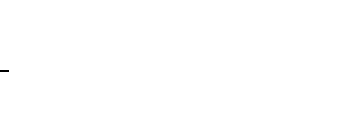 & $\begin{array}{c}\text { Baik } \\
\text { Baik }\end{array}$ & $\begin{array}{l}\text { Sesuai } \\
\text { Sesuai }\end{array}$ & $\begin{array}{c}\text { Baik } \\
\text { Baik }\end{array}$ & $\begin{array}{l}\text { Sesuai } \\
\text { Sesuai }\end{array}$ \\
\hline 6. & $\begin{array}{l}\text { Penetrasi } \\
\text { Minyak }\end{array}$ & $7-15 \mathrm{~mm}$ & $7,866 \mathrm{~mm}$ & Seuai & $8,311 \mathrm{~mm}$ & Sesuai \\
\hline 7. & $\begin{array}{l}\text { Daya Serap } \\
\text { Air (Cobb) }\end{array}$ & $20-40 \mathrm{~g} / \mathrm{m}^{2}$ & $46,2 \mathrm{~g} / \mathrm{m}^{2}$ & $\begin{array}{l}\text { Tidak } \\
\text { sesuai }\end{array}$ & $22,702 \mathrm{~g} / \mathrm{m}^{2}$ & Sesuai \\
\hline
\end{tabular}




\begin{tabular}{|c|c|c|c|c|c|c|}
\hline \multirow{3}{*}{8.} & Sifat & \multirow{5}{*}{ Tidak patah } & & & \multirow[b]{3}{*}{ Baik } & \multirow[b]{3}{*}{ Sesuai } \\
\hline & Lipatan & & \multirow[b]{2}{*}{ Baik } & \multirow[b]{2}{*}{ Sesuai } & & \\
\hline & MD & & & & & \\
\hline & \multirow{2}{*}{$\mathrm{CD}$} & & \multirow{2}{*}{ Retak } & Tidak & \multirow{2}{*}{ Retak } & Tidak \\
\hline & & & & Sesuai & & Sesuai \\
\hline 9. & Kadar air & Maks.10\% & $5,15 \%$ & Sesuai & $4 \%$ & Sesuai \\
\hline
\end{tabular}

\section{KESIMPULAN}

Berdasarkan penelitian yang telah dilakukan yang menjadi fokus utama dalam penelitian ini adalah karton duplex $350 \mathrm{~g} / \mathrm{m} 2$ produksi PT X. dan PT Y., hasil penelitian dapat disimpulkan sebagai berikut:

1. Pengujian karton duplex produksi PT X. dan PT Y., yang dilakukan di Laboratorium pengujian bahan grafika Politeknik Negeri Media Kreatif Jakarta berdasarkan Standar Opersioanl Prosedur (SOP) yang terdapat didalam Buku Pedoman Pengujian Kertas dan Tinta dan berdasarkan Standar Nasional Indonesia untuk persyaratan mutu karton duplex (SNI 0123:2008).

2. Terdapat beberapa hasil pengujian karton duplex produksi produksi PT X. dan PT Y., yang telah memenuhi persyaratan mutu karton dupex, yaitu komposisi lembaran, gramatur, rapat massa, ketahanan cabut lapisan atas, penetrasi minyak lapisan atas, sifat pelipatan, dan Kadar air. Selain itu, terdapat perbedaan mutu antara karton duplex produksi produksi PT X. dan PT Y., yaitu untuk karton duplex produksi PT Y. tidak memenuhi persyaratan mutu untuk nilai derajat putih berdasarkan SNI 0123:2008. Sedangkan, untuk karton duplex produksi PT Y., tidak memenuhi persyaratan mutu untuk nilai daya serap air (Cobb) lapisan atas berdasarkan SNI 0123:2008.

3. Dari hasil data pengujian, dapat disimpulkan SNI 0123:2008 disusun dengan tujuan standarisasi, namun ketentuan standar tidak terpenuhi dan tidak terawasi pada perusahaan yang tidak menerapkan standar SNI 0123:2008, namun di perusahaan yang menerapkan standar SNI 0123:2008 ditemukan juga ketidak sesuaian, untuk itu disarankan dilaksanakan pemantauan secara berkala.

\section{REFERENSI}

Amri, L. H. A., \& Wijayanti, R. A. 2019. Pemanfaatan Sistem Informasi Geospasial Online Untuk Mendukung Pengambilan Keputusan Pemanfaatan Tata Ruang. Jurnal Teknologi Informasi Dan Terapan, 6(2), 62-66. 
https://doi.org/10.25047/jtit.v6i2.111

Brody, Aaron L. dan S. rsh, Kenneth. 1997.

The Wiley Encyclopedia Of Packaging

Technology. 2nd. United States of America (USA)

Djamara, Tabarani. 2018. Pengetahuan

Kertas dan Karton. Politeknik Negeri

Media Kreatif Jakarta.

Erliza dan Sutedja. 1987. Pengantar

Pengemasan. Bogor: Laboratorium

Pengemasan Jurusan TIP IPB.

Gasperz, Vincent. 2001. Total Quality

Management. Jakarta: Gramedia

Pustaka Utama.

Kurniawan, E. 2011. Perbandingan
Keefektifan Metode Observasi dan DiskusiTerhadap Hasil Belajar Biologi Pokok Bahasan Ekosistem (Skripsi). IAIN Walisongo: Semarang

Muchtar, Efnyta. dkk. 1998. Pedoman Pengujian Kertas dan Tinta. Jakarta. Pusgrafin.

Nazir, M. 1988. Metode Penelitian. Jakarta: Ghalia Indonesia Nugrahaeni, Mutiara. 2018. Kemasan Pangan. Yogyakarta: Plantaxia.

Syarief, R. dan Irawati, 1988. Pengetahuan Bahan untuk Industri Pertanian. Jakarta: Mediayatama Sarana Perkasa 